\title{
DIRCE, MESTRA EM MOCIDADE
}

Luiz Costa Lima

(PUC-Rio/UERJ/CNPq)

Procuro conceber como seria a pessoa que me acolheu, no Rio de Janeiro, em fins da década de 1960. Como não me basta dizer a mim mesmo como aprendi a querê-la bem, e como a memória vê pouco e o que guarda é sempre escasso, tento outro caminho. Procuro, em suma, reconstituir aquela que, a partir do nada de conhecimento, seria a Dirce que me protegia.

Bem sei como nos enganamos sobre nós mesmos. Recorro por isso a dados de superfície que, sendo lisos, não serão duvidosos.

Quando nos soubemos um do outro, eu tinha cerca de trinta e poucos anos. Chegara ao Rio alguns anos antes, em fins de 1964 e, enquanto hospedado no Hotel Novo Mundo, escutara, na Hora do Brasil, que ingressara na lista dos punidos pelo Ato Institucional, $n^{\circ} 1$. Encontrar-me no Hotel, fora parte de um ato de sorte: alguém me convidara a participar de um seminário em local que já ignoro e, pela proposta, tivera pagas a passagem aérea desde o Recife e alguns dias de hospedagem. Enquanto estive no Hotel, entrei em contato com uma prima que já morava no Rio e tive assegurada um local de estadia mais longa. Já me encontrando em seu apartamento, a sequência de atos de sorte fez com que, por meio de José Guilherme Merquior, a quem só conhecia por correspondência, fosse apresentado à sua ex-mestra, Dirce Côrtes Riedel.

A Dirce e à sua filha adotiva, Teresa, logo deveria os convites para dar alguns cursos que me ajudariam a sobreviver, enquanto não conseguisse um emprego fixo. O primeiro deles foi dado em uma escola secundária de aperfeiçoamento, mantida excepcionalmente em Niterói. O segundo era um curso sobre sociologia da literatura, oferecido na UERJ.

Ao recordá-lo, percebo que ainda não compreendia a seriedade do que o golpe de abril de 1964 representava para a vida do país. Tanto assim que escolhia como um de meus primeiros temas o texto do crítico norte-americano Kenneth Burke, em que era analisado o Minha luta (Mein 
Kampf), de Hitler. Embora não lembre o que eu próprio dizia a respeito, a escolha era uma flagrante provocação. Como não me incomodara com isso, a responsabilidade indiretamente recaía sobre quem me convidava. Tanto assim que, logo depois da aula, alguém me pedia que tivesse mais cautela. Este deve ter sido o primeiro risco que fiz Dirce correr por ajudar o benjamin dos aposentados. Se não me arrependo por esta primeira ousadia, não posso deixar de me penitenciar pelos perigos que fazia minha amiga correr. E ao escrever o que ora escrevo, compreendo que o dilema era inevitável: sem a ajuda de Dirce e de Teresa, minha sobrevivência teria sido muito mais difícil; no entanto, elas não me teriam ajudado sem correr o risco que correram. (Não continuo por esse meandro porque chegaria à hipótese apenas provável. Digo apenas, embora seja possível que a ajuda que me prestavam tenha, adiante, ajudado à perseguição de pessoa a elas - e a mim - bastante próxima).

A situação em que o "aposentado" se encontrava era mais grave porque ele não já não estava sozinho. Efeito indireto do golpe, casara-se pouco depois de sair da prisão; dispondo no Rio do apartamento de uma prima, tinha como mandar buscar sua mulher. Para não entrar em detalhes desnecessários, apenas direi que, nos anos próximos, tinha como sustentar a família e ela já estava acrescida de dois filhos.

Meus primeiros empregos, como revisor da Editora Vozes, anos depois, como membro da equipe chefiada por Antonio Houaiss e Otto Maria Carpeaux, responsáveis pela elaboração da Enciclopédia Delta-Larousse, me permitiam e a meus familiares uma estrita sobrevivência. Isso não impedia a sensação de viver sob o fio de uma navalha, evidente por estar cercado pelas armas repressivas dos que haviam optado pela salvação "democrática". Pensado a partir da ótica de hoje, o "emigrado" permanecia um homem jovem e os riscos que corria - por mais que isso hoje lhe pareça inconcebível - deviam-lhe parecer leves. Sem nunca haver sido um otimista, creio que não sabia o que fosse depressão. Daí o risco iminente de novas encruzilhadas.

Poucos anos depois de instalado no Rio, separei-me e tive de deixar o apartamento em que vivera com minha família. É especificamente aqui que Dirce ultrapassa sua condição de sombra protetora. Como não teria de pagar um apartamento apenas para mim, Dirce de imediato cedeu um quarto de onde morava, na República do Peru, Copacabana.

Ali, por volta de um ano, convivi com Dirce e Teresa, tendo a companhia constante de Ivo Barbieri, que já mantinha uma relação amorosa 
com Teresa. Hoje, me parece inacreditável como toda essa sobrecarga me parecia leve. Perdera a posição de professor universitário apenas com um pouco mais de um ano de serviço, fora afastado da cidade que havia sido minha por quase todo vida, passara a conviver com um lugar que até então desconhecera, assumira a posição de marido e pai antes que tivesse condições efetivas de sê-lo, recuperara minha liberdade existencial, no entanto cercado pela ameaça de grades bem cerradas, e, no entanto, esquecia todo o peso pelo convívio de que partilhava na República do Peru. Confesso meu espanto com o que esquecera de mim próprio.

Meu tempo se dividia entre as idas diárias ao centro da cidade, para o trabalho na Enciclopédia e as aulas que dava no Departamento de Sociologia, da PUC (RJ), em que era professor horista, graças ao convite de seu diretor, o Pe. Ozanam - que logo desapareceria, sem que jamais soubesse de seu destino. No apartamento de Dirce, as horas livres, se não eram muitas, eram por certo divertidas, agradáveis, mesmo alegres. Nele, tinha como ocupação principal pesquisar na imensa biblioteca de minha protetora. Como não deveria ter sequer transportado os poucos livros que já recebera da casa de meus pais, e não devia ter recursos para comprar novos, dependia da riqueza de seu acervo. Recordo com a máxima nitidez que foi, em sua coleção da Pléiade, que li toda a Recherche proustiana (quando hoje recorro meus exemplares, acho curioso que seus tipos, no entanto os mesmos, agora me pareçam tão pequenos). Se dissesse que me via como um pobre perseguido, esmagado pela repressão que triturara a equipe formadora dos alfabetizadores de Paulo Freire, que perdera meu emprego estável com menos de 30 anos, e fora separado dos que haviam sido meus amigos de adolescência seria uma estúpida mentira. Ela não seria menor se declarasse que tinha uma vida de trabalhador e asceta, sem outra perspectiva senão obrigações e sacrifícios. Nada disso seria verdadeiro. Não suponho sequer que tivesse de pedir licença a Dirce para receber, no meu quarto, minha namorada. Na verdade, as conversas com Dirce, Teresa e Ivo, os grupos de estudos que formávamos - e denúncias que provocavam! -, o convívio com os livros a meu dispor, as anotações incessantes que escrevia e os encontros noturnos, supostamente clandestinos, constituíam, em conjunto, um dos poucos períodos felizes que conheci na vida.

Por certo, em algum momento, tive de dispor de um apartamento para mim. Sequer me pergunto de onde tirava os meios para me sustentar. Nunca pretendi converter meu pai em responsável por uma decisão polí- 
tica que havia sido e continuava só minha. É certo que devia à minha mãe haver dele arrancado o dinheiro para a compra do apartamento onde vivia minha ex-família (D. Elza, minha mãe verdadeira, encontrava seu seguimento em Dirce, no Rio). O fato é que, talvez por artigos que traduzia para a Vozes e pelas colaborações extras para a Enciclopédia, que devia a meu querido Carpeaux, nunca me tornei um inadimplente ou um mau pagador. Seria uma sobrevivência muito estrita, da qual, provavelmente, não mais tenho a dimensão exata. Lembro-me apenas aleatoriamente haver certa vez recebido a visita de um frade, tradutor de Saint-John Perse, amigo de Pedro Paulo Sena Madureira, que, ao se despedir, me dizia que meu apartamento era mais pobre que sua cela.

Nada disso me incomodava. Durante anos, vivi entre aquele apartamento, na rua Lauro Müller, o trabalho na Enciclopédia, as idas com Carpeaux e um colega de trabalho às passeatas no centro da cidade,as aulas na PUC e as constantes visitas à República do Peru.

No fim da década de 1970, cansei-me do ramerrão em um país que parecia mergulhado em trevas sem limites, e prestei exame para uma universidade norte-americana. Sendo aprovado, já de novo casado e com um filho bem pequeno, no fim de 1981, segui para Minneapolis. Ao partir, pensava que me despedia definitivamente de meu país. Mas a esperança de encontrar um ambiente intelectualmente saudável foi quase de imediato frustrado. Poucas semanas bastaram para que eu soubesse que aproveitaria o interregno dos dois anos e meio anteriores a meu pedido de permanência (tenure) para que logo a recusasse. Assim meus anos em Minneapolis foram quase integralmente preenchidos por meu tempo na magnífica biblioteca da Universidade de Minnesota, à qual devo os dois livros que, entre 1982 e 1983, lá escrevi.

Em meados de 1984, sem nenhum arrependimento, estava de volta. (Entre parênteses, sem maiores explicações, fique claro que deixo sem explicar muita coisa. Não saberia sequer do posto disponível na universidade norte-americana sem o informe do professor polaco-americano Wlad Godzich; assim como não o teria conhecido sem a mediação de Wolf-Dieter Stempel, em visita ao Rio, e, em consequência, de Hans Ulrich Gumbrecht, quando da inesperada visita à Universidade de Konstanz. Mas explicar a participação dos três levaria a ampliar desproporcionadamente este depoimento).

Como antes de viajar para os Estados Unidos, pela ajuda inestimável de Antonio Candido, pudera defender minha tese em Teoria da 
Literatura, na USP, ao optar pelo retorno, podia ser professor de tempo contínuo na PUC. Ademais, a ditadura perdia sua força e a anistia dos antes atingidos pelos Atos Institucionais me permitia, pela transferência à Universidade Federal de Niterói, uma certa tranquilidade financeira.

É exatamente aqui que, outra vez, Dirce desempenha todo seu papel, em minha vida afetivo-profissional. Provavelmente, antes de minha volta, estando Ivo Barbieri como reitor da UERJ, Dirce, com a colaboração de amigos, como o professor Roberto Acízelo, decidira organizar a abertura do curso de pós-graduação em Letras, da Universidade do Estado. Pouco depois de meu retorno, eu fora aprovado em concurso que fizera para a UERJ. Tornava-se assim administrativamente possível ser convidado para participar da organização da pós-graduação. Como, além do mais, logo completei meu tempo de serviço na Universidade Federal, passava a dividir minhas obrigações entre a PUC e a UERJ. Para quem, enquanto antes tinha estado no Brasil, os salários, por seu trabalho universitário, constavam do minimamente necessário, passava a ter a remuneração modesta e usual entre os professores do país.

Evito falar da vida que o ex-aposentado passava a ter, a partir de 1985 ou 1986. Falar na esperança que então tínhamos se constituir um ensino de qualidade exigiria um espaço já agora desproporcional. Para o que motivou este depoimento bastará dizer que, pela ajuda recebida de várias fontes, o AI/1 não criou um anônimo bastardo ou uma criatura ressentida e amargurada. Entre os que o ajudaram, destaco a figura de minha saudosa Dirce Côrtes Riedel. E do muito, talvez até excessivo número de páginas que tenho escrito, umas das poucas afirmações acertadas consistiu em chamá-la, na dedicatória de um de meus livros, de mestra em mocidade. Não antes, nem depois, conheci alguém que se conservasse tão jovem, lúcida e corajosa como Dirce Côrtes Riedel.

O que, no começo, a memória dos sentidos não me permitia fixar, as palavras agora o conseguiram.

Rio de Janeiro, abril de 2016.

Recebido em: 14 de outubro de 2016

Aceito em: 20 de outubro de 2016 